\title{
LA REVOLUCIÓN COMO ASCESIS DE UNA ÉTICA MATERIALISTA EN MICHEL FOUCAULT
}

\author{
Revolution as an Askesis of a Materialist Ethics in Michel Foucault \\ Julia Monge \\ Universidad Nacional de Córdoba \\ julia_monge@hotmail.com
}

\begin{abstract}
Resumen:
Teniendo en cuenta las críticas que condujeron a Michel Foucault en los años setenta a tomar distancia de la revolución como paradigma de todas las resistencias, el presente trabajo explora el "retorno de la revolución" como figura positiva en sus últimas indagaciones. A partir del proyecto de estudiar la subjetividad revolucionaria que el profesor plantea y deja sin desarrollar, se reconstruyen las menciones del tema en sus cursos entre 1980 y 1984, clarificando la consideración de la revolución como figura ascética. Recuperando la lectura que Foucault propone del Cinismo como matriz de la vida militante, se sugiere entender allí la elaboración de una ética materialista que no sólo explica la revolución como ascesis, sino que encuentra su realización en luchas actuales.
\end{abstract}

\section{Palabras clave:}

Revolución, ascesis, ética materialista, Foucault, cinismo.

\begin{abstract}
:
Considering the objections that in the seventies led Michel Foucault to take distance from revolution as a paradigm of all forms of resistance, this paper explores the "return of revolution" as a positive figure in his last lectures. Taking the project of studying the revolutionary subjectivity that the professor formulated but left undeveloped, we reconstruct the mentions of the topic in his courses between 1980 and 1984, and we clarify as a result the consideration of revolution as an ascetic figure. Recovering Foucault's interpretation of Cynicism as the matrix of the activist life, we suggest to understand it as the elaboration of a materialist ethics, which explains revolution as an askesis and finds its realization in present experiences.
\end{abstract}

\section{Keywords:}

Revolution, Askesis, Materialist Ethics, Foucault, Cynicism.

Recibido: $14 / 05 / 2019$

Aceptado: 10/06/2019 


\section{INTRODUCCIÓN. NORMA Y DESEO DE LA REVOLUCIÓN}

Son conocidas las reformulaciones del entendimiento del saber, el poder y la historia desde las cuales Michel Foucault criticó la ortodoxia teórico-práctica del Partido Comunista Francés y el marxismo académico'. La inconveniencia de recurrir a la oposición ciencia-ideología para abordar la producción y circulación social de los saberes tanto como su incidencia en los modos de subjetivación; el desplazamiento de las ideas de contradicción, dialéctica y la centralidad del Estado para pensar las relaciones y el ejercicio del poder; la adopción de una perspectiva genealógica que discrepa de la definición de una causalidad única o factor determinante -a la vez que cualquier tipo de teleología- para comprender la historia; constituyen los puntos salientes de tal confrontación. En conjunto, estos desacuerdos condujeron a Foucault como un corolario en medio de otros- a interponer recaudos para considerar la revolución como paradigma de toda insurrección.

En “¿Es inútil sublevarse?", cierre de la serie de artículos que el profesor francés escribió cubriendo la revolución iraní de $1978^{2}$-pero donde avanza una reflexión que la excede-, condensa la tensión de sus reservas. Como "maravilloso y temible" presenta el esfuerzo de la revolución "por aclimatar la sublevación en el interior de una historia racional y dominable", discriminando sus buenas y malas formas y fijándole así sus condiciones previas, reglas de desarrollo y maneras de cumplirse, para "hacerla aparecer en su verdad y conducirla hasta su término real" (2010a: 862). Promesa de una marcha implacable, cuya atracción no puede subestimarse en un movimiento en que tanto el riesgo como las posibilidades de vida guardan relación con la radicalidad de la transformación que se persigue; más aún, con la inscripción en la historia de una amenaza tan eventual como inevitable para todos los despotismos: el hecho de que se puede preferir el sacrificio ante la certeza de tener que obedecer. Promesa ominosa, si

\footnotetext{
${ }^{1}$ La relación de Foucault con el marxismo constituye sin duda una de las más destacadas y polémicas. Trabajos como los de Read (2003), Lemke et al. (2006), Choat (2010), Garo (2011) y más recientemente los reunidos en la compilación Marx \& Foucault. Lectures, usages, confrontations provenientes de un coloquio realizado en 2014 en París -del cual utilizaremos algunos artículos-, demuestran una labor continua y actual abocada a pensar sus diferentes aspectos y dimensiones, afinidades y desencuentros. Por mor de la extensión y atendiendo al asunto específico que nos ocupa, nos apartaremos aquí de su consideración ampliada limitándonos a recuperar algunas críticas de Foucault al PCF y teniendo en cuenta que diferenciaba dentro del marxismo a "ciertos espíritus petrificados" por el dogmatismo, y el "intento de comprender, en su complejidad, el conjunto de relaciones que han constituido nuestra historia, como intento de determinar en qué coyuntura nuestra acción es posible hoy", gracias al cual "afortunadamente, es otra cosa" que lo primero (Foucault, 2013a: 78).

${ }^{2}$ La posición y reflexiones de Foucault en torno a la revolución iraní han sido revisitadas profusamente por las exégesis en los últimos años. Para dichas referencias sobre el tema, así como para encuadrar la lectura que aquí proponemos, nos permitimos indicar Monge (2018).
} 
conlleva la institución de una ley para vivir la revolución, aceptando un ordenamiento (temporal y axiológico) de las necesidades, objetivos y deseos que implica la depreciación y postergación de ciertas luchas por considerarlas marginales $y$, correlativamente, la definición de un Sujeto revolucionario auténtico que puede resultar al cabo, aun bajo el signo de la liberación, tan coactivo como las identificaciones que impone el status quo.

Poner en guardia, por un lado, contra el establecimiento de una norma para legitimar las luchas y calificar la validez de la sublevación; sin dejar de dar lugar, por otro, al reconocimiento del hecho irreductible que distingue a la revolución: la desobediencia innegociable que enfrenta a un poder con el fin de revocarlo y transformar la realidad. Tal es la preocupación que por debajo del plan revolucionario y sus necesidades estratégicas, y por detrás del desajuste entre el programa y su realización material, recupera Foucault como núcleo íntimo de la interrogación por el ocaso o pervivencia de la revolución. En más de una ocasión señala los "efectos despóticos" que pudo tener "el monopolio de la revolución" sobre luchas en apariencia menores, como las dadas en torno a la locura, las relaciones sexuales, la prisión, las jerarquías familiares; las cuales alejadas del proceso "global y unitario" que aseguraría "la liberación total", también buscan una desestabilización de los mecanismos de poder sin recaer en el reformismo (Foucault, 2010b: 794). Y sin embargo, frente a quienes podían sentenciar sin incomodidad que la revolución "fue colonizada en la Real-Politik", seguía prefiriendo "la pregunta que Horkheimer planteaba en otra ocasión, pregunta ingenua, y un poco febril: «Pero, ¿es, pues, tan deseable, esta revolución?»" (Foucault, 2010a: 862).

La cuestión del deseo de la revolución ya había sido formulada por el profesor un par de años antes, especificada de una manera en que no se trataba, como parece allí, de la valoración del hecho consumado. Tampoco de un fenómeno separable de los resultados, como el que Kant identificó en el entusiasmo - postura que analizará tiempo después y sobre la que volveremos. En una entrevista de 1976 y otra de 1977, para Foucault se trata de que la revolución fue efectivamente deseada, y de la posibilidad y forma en que pueda seguir siéndolo.

No podemos suscitar la aspiración a la revolución sembrando el terror en la gente. En el s. XIX la revolución fue deseada por las masas. Pero el estalinismo, los acontecimientos que le sucedieron y los fenómenos que la revolución comunista produjo como muestras en distintas partes del mundo, terminaron por hacer bajar considerablemente la tasa de deseabilidad de la revolución [...] Es urgente restituir a la revolución los encantos que tenía en el s. XIX. Para ello, es necesario inventar nuevos modos de relaciones humanas, es decir, nuevos modos de saber, nuevos modos de placer y de vida sexual. Me parece que el cambio de esas relaciones puede transformarse en una revolución y volverla deseable. En suma, la formación de nuevos modos de relaciones humanas constituye un tema indispensable para hablar de revolución (Foucault, 1994: 85-86). 
La revolución como ascesis de una ética materialista en Michel Foucault

El retorno de la revolución es nuestro problema [...] Si queremos hacer una política que no sea de politicastros, debemos preocuparnos de averiguar con la máxima honradez posible si la revolución es o no deseable (Foucault, 2000a: 160-161).

En esta clave, se comprende por qué la imposibilidad de plantear la experiencia revolucionaria más que en términos de una "voluntad monolítica" garantizada por la pertenencia al partido y practicando un puritanismo moral gemelo de los valores burgueses, haya sido objetado por Foucault al PCF con la misma seriedad que le confrontó su evasiva a hablar del Gulag (Cfr. Foucault, 2012; 2010c). De igual modo que, en repetidas oportunidades, consideró la Unión Soviética como un ejemplo de que el Estado puede cambiar de manos y las formas de vida permanecer similares a las de la sociedad capitalista, si la transformación de las estructuras político-económicas no es acompañada de una liberación del conservadurismo cultural que rige sobre todas las relaciones que traman la existencia cotidiana (Cfr. Foucault, 2010d; 2010e).

Con todo, la inquietud por la revolución no estaba saldada para Foucault por exponer las cegueras y restos que contrastan "nuestra novelita de amor secular por el socialismo" y atender a los cuerpos, energías, lo que hacen, dicen y piensan quienes vivieron y se alzaron contra su realización sombría (2000b:76). Quedaba en pie -y precisamente a partir de ello- el "enigma" de la sublevación, que al igual que la cuestión del deseo, introduce con respecto de la revolución una perspectiva diferente de su estimación como gran proceso de conmoción política y económica, con sus problemas asociados a la violencia, la burocratización de su programa, la estratificación de las urgencias, su inversión despótica y su fortuna hermanada con la tragedia. Asunto en cierto modo lateral pero a la vez en el corazón de su ocurrencia y persistencia histórica; secreto de la sublevación como "punto de anclaje último" de "todas las formas de libertad adquiridas o reclamadas y de todos los derechos que se hacen valer" (Foucault, 2010a: 861): se trata de la pregunta por la subjetividad revolucionaria, subjetivación ético-política tan indócil a la dominación como a su objetivación teórica.

Después de haber estudiado el problema histórico de la subjetividad a través del problema de la locura, del crimen, del sexo, quisiera estudiar el problema de la subjetividad revolucionaria. Ha llegado el momento de estudiar la revolución no solamente como movimiento social o transformación política, sino también como experiencia subjetiva, como tipo de subjetividad (Foucault, 2017: 109).

Habría que hacer una historia de las técnicas de sí y las estéticas de la existencia en el mundo moderno [...] Podríamos concebir la Revolución no simplemente como un proyecto político sino como un estilo, un modo de existencia con su estética, su ascetismo, las formas particulares de relación consigo mismo y los otros. (Foucault, 2013b: 221). 
Esa incógnita que impedía a Foucault condenar a la revolución porque, a pesar de los pesares, en ella "la subjetividad (no la de los grandes hombres, sino la de cualquiera) se introduce en la historia y le da su soplo" (2010a: 863), pero a la vez le hacía preferir hablar de "resistencias" para no encerrar en un esquema hegemónico la variedad de luchas y objetivos; asume en sus indagaciones de los años ochenta la especificación como tema de problematización. Mencionado en distintas ocasiones y en medio de otras investigaciones, quedará sin embargo como una sugerencia en suspenso, ya que no llega propiamente a desarrollarlo.

Con lo expuesto hasta aquí como telón de fondo y reconstruyendo a continuación esas indicaciones que deja el profesor, nos interesa indagar este singular "retorno de la revolución" en sus últimos planteos entre 1980 y 1984. En el marco de las técnicas ascéticas y artes de vivir antiguas que allí explora, el tema de la subjetividad revolucionaria puede ser esclarecido en particular desde las claves de una ética materialista que a nuestro entender Foucault elabora, no sólo pero sí de manera eminente, en su tratamiento del Cinismo como matriz de la vida militante y ética de la verdad que ha trascendido en distintas prácticas históricas. A la par de otras experiencias, la revolución vuelve a ser en efecto nombrada por el profesor en su último curso; en una reflexión tan tensada de actualidad que hace dudar si, con respecto del Cinismo, constituye un epígono de la vieja inquietud que enlaza el problema de la verdad con el de las formas de vida, o si en cambio, condensa el núcleo de experiencia que Foucault intenta hacer aparecer en aquella vida escandalosa para la cultura antigua y en una ética para el presente.

\section{LA INQUIETUD POR LA SUBJETIVACIÓN REVOLUCIONARIA Y LA REDEFINICIÓN DE LA ASCESIS}

Emprendiendo la reconstrucción en orden cronológico, el curso de 1980 Del gobierno de los vivos en el cual Foucault avanza decisivamente hacia el análisis de los procedimientos subjetivos que aseguran el enlace con la verdad ${ }^{3}$, constituye el primer contexto de consideración. Aquí aparecen dos menciones a la revolución que traducen en cierto modo el desplazamiento de enfoque señalado en el apartado anterior: como proceso que supone una conexión entre ejercicio de poder y juego de verdad, y como experiencia subjetiva ligada a una codificación.

\footnotetext{
${ }^{3}$ En este curso Foucault propone una segunda definición de "régimen de verdad" que descubre una faz complementaria la que propuso en 1971: mientras ésta hacía referencia a los mecanismos e instancias mediante los cuales se reglamenta socialmente la producción, circulación y validación de los discursos verdaderos "ligados circularmente con sistemas de poder" (2010f: 389-391), aquí designa "las obligaciones de los individuos en lo referido a los procedimientos de manifestación de lo verdadero" (2014a: 115 y ss.); es decir, las operaciones que deben efectuar sobre sí mismos para constituirse en sujetos ligados a la verdad. En conjunto, el régimen de verdad comprende tanto las operaciones y estrategias para objetivar y configurar subjetividades, como las prácticas que los individuos efectúan sobre sí mismos en relación con ellas (en colaboración u oposición) para auto-constituirse como sujetos; dos caras que no se excluyen mutuamente sino que funcionan entretejidas.
} 
El primer caso se da en una reconstrucción esquemática de cinco grandes formas a través de las cuales el pensamiento político moderno asumió la relación entre gobierno y manifestación de la verdad. Luego del "principio de Botero" -la verdad del Estado como objeto de la acción gubernamental-, el "principio de Quesnay" -la evidencia del funcionamiento de la sociedad y la economía dispensando de grandes decisiones e intervenciones-, y el "principio de Saint-Simon" -constitución de un saber especializado para transformar el gobierno en una administración de tipo tecnocrática-; las dos maneras restantes involucran a la revolución en sentidos opuestos. Por un lado, se trata de la "toma de conciencia general" que plantea la incompatibilidad entre conocer la verdad sobre el funcionamiento de la sociedad, los procesos económicos, los mecanismos de dominación, y el ejercicio del gobierno por parte de algunos. Si todo el mundo supiese la verdad del mundo en que vive, descubriera cómo realmente se sostiene el orden, "el gobierno simplemente ya no podría gobernar, y se produciría de inmediato una revolución" - principio del "despertar universal" que conlleva el derrocamiento de los regímenes y sistemas, atribuido por Foucault a Rosa Luxemburgo. Simétrica e inversa se define la lógica del terror o último "principio de Solzhenitsyn"4: es precisamente porque los gobernados saben bien lo que pasa, porque el poder no oculta su obscenidad, que las cosas no se mueven y "los regímenes socialistas duran" (2014a: 32-36).

Foucault recusa todos los modelos en conjunto aduciendo que, centrados en la sociedad o el Estado y entendiendo el conocimiento de la verdad en términos de su utilidad para la eficacia del gobierno, no permiten abordar el "nivel mucho más profundo" e históricamente lejano del lazo en cuestión. La pregunta rectora de este curso es precisamente por qué en nuestras sociedades el poder no puede ejercerse sin demandar a los sujetos no sólo actos de obediencia sino que se configuren como actores, espectadores, testigos u objetos de una manifestación de la verdad cuyos efectos involucran la salvación y liberación para cada uno y para todos. En el marco de una historia de la verdad que parte de esos actos de subjetivación en cuanto requieren una relación entre verdad y ascesis, verdad y experiencia "en el sentido cabal y fuerte del término", como "aquello que, a la vez, califica al sujeto, lo ilumina acerca de sí mismo y del mundo, y lo transforma" (2014a:138), se introduce la segunda mención.

A partir de la recuperación de tres grandes matrices del pensamiento moral occidental conforme a las cuales la moral pudo plantearse como arte de la conducción de los individuos, Foucault señala su aparición en el ideario revolucionario. La caída y la redención, la elección entre dos vías, y la mancha original que hay que purificar, podrían reconocerse respectivamente en la alienación y desalienación en Marx, en Mao Tse-Tung como decisión ante decursos contrapuestos, y en el estalinismo como purga de

\footnotetext{
${ }^{4}$ Foucault ya menciona a A. Solzhenitsyn, representante destacado de la disidencia antisoviética, en el contexto de la introducción del término "contraconductas" en el curso de 1978 (2006: 236238), y de nuevo en las clases del año siguiente (2007: 156, véase aquí la nota al pie que conduce a otras referencias).
} 
la impureza. Revelarle a la humanidad cómo remontarse a su estado originario, indicarle el buen camino y enseñarle a borrar su mácula, representan para Foucault formas en que pensó la transformación ética involucrada en la agencia revolucionaria (135-136). Que el cristianismo haya sido la otra experiencia que supo componer las tres matrices, comporta para el profesor un índice más de que el esquema de la ideología resulta inadecuado para dar cuenta de las complejas relaciones entre gobierno y ascetismo (Cfr. 30-31; 96-99). En efecto, en las lecciones del año siguiente en el Collège de France Subjetivité et vérité, si bien la revolución no es aludida, vuelve a señalarse la insuficiencia del análisis en términos de ideología para explicar la función de los discursos verdaderos como "técnicas" para la elaboración reflexiva del modo de ser y comportarse (Cfr. 2014b: 242-245).

En esta línea se inscriben las siguientes referencias que aparecen en Hermenéutica del sujeto, curso de 1982. En primer lugar, se trata de una mención complementaria a la de 1980. Planteando cierto resurgimiento en las filosofías del s. XIX de la estructura de espiritualidad vinculada al acto de conocimiento -la cual, presente en la antigüedad y disuelta en la modernidad, suponía la necesidad de una ascesis para tener acceso a la verdad-, Foucault incluye al psicoanálisis y al marxismo. En el "corazón" de este último se halla la cuestión de lo que debe ser el ser del sujeto y de lo que puede transformarse en él por saber la verdad; aunque fue un tema que en la práctica no se consideró "de manera clara y valerosa", intentando en cambio enmascarar esa dimensión espiritual en "una serie de formas sociales" - la condición de clase, la pertenencia al partido, las exigencias de la organización (2008: 43).

En segundo lugar, ocupándose de la conversión como "una de las tecnologías del yo más importante que conoció Occidente", Foucault hace una digresión para señalar que su relevancia para la historia de la subjetividad no sólo es filosófica y moral, sino que tuvo su "dramática introducción en la vida política del s. XIX", cuya consideración implicaría "hacer la historia de lo que podríamos Ilamar la subjetividad revolucionaria". A su entender, ni en la revolución inglesa ni en la francesa se planteó el tema de definir esquemas de experiencia individual y subjetiva para "la conversión a la revolución" motivo sin el cual, en cambio, no serían comprensibles la práctica revolucionaria y el individuo revolucionario a partir del s. XIX. Aunque habría que indagar cómo esa antigua técnica de sí "se ligó exclusivamente a la opción revolucionaria"; el profesor restaura sus recaudos indicando que sería preciso atender a la forma en que fue luego "absorbida y por fin anulada por la existencia misma de un partido revolucionario", que sustituyó la necesidad de la conversión por el requisito de adhesión a una organización estructurada de conducción y representación. No volviéndola a mencionar en el resto del curso, la última apreciación que cierra este sugerente paréntesis, es que "ahora ya sólo nos convertimos a la renuncia a la revolución. Los grandes conversos de nuestros días son quienes ya no creen en la revolución" (206-207).

Dos meses después, en unas conferencias y seminario que dicta en la Universidad Victoria de Toronto, Dire vrai sur soi-même al igual que el curso de 1981, aún sin 
traducción al español- es donde repite su intención de estudiar la subjetividad revolucionaria que citamos en el apartado precedente. En línea con la asociación anterior a un motivo determinado, Foucault especifica aquí un encuadre problemático centrado en el sentido de la ascesis. A partir de la diferencia entre su orientación en la cultura de sí antigua y en la espiritualidad cristiana, y como categoría importante de la ética y del análisis histórico que vuelve a aparecer en Nietzsche y Weber, el profesor propone una redefinición de la noción comprendiendo las dos grandes formas que revistió en la civilización occidental.

Desplazándose del significado habitual de ascesis que la reduce a algún tipo de renuncia, Foucault sugiere entenderla como "una transformación de sí voluntaria y costosa, gracias a un conjunto de técnicas regladas, que tienen por meta no la adquisición de una aptitud o conocimiento sino la transformación de sí en el modo de ser" (2017: 108). En esta clave, reconoce en ella dos modalidades principales: la ascesis orientada hacia la verdad y la ascesis orientada hacia la realidad. El fin de la primera, correspondiente al esquema antiguo, es hacer de la verdad la regla de nuestra relación tanto con nosotros mismos como con el mundo; de modo que adquirir la verdad es la vez el objetivo y el medio por el cual hay una interconexión y reciprocidad entre el gobierno de sí y la capacidad de afrontar los acontecimientos del mundo. La segunda, desarrollada en las tecnologías de sí cristianas, tiene en cambio por objeto ir de una realidad hacia otra, según un "rito de pasaje" desde un sí mismo, una vida y un mundo aparentes a los que es preciso -aquí sí- renunciar, para acceder a otro mundo que es el verdadero y plenamente real.

Advirtiendo que no deben pensarse como formas incompatibles y excluyentes, sino imbricadas con dificultades y tensiones que han atravesado desde su posible ajuste en el platonismo, su desequilibro entre la Reforma y la Contra-reforma, su transformación en la Ilustración, sus conflictos en las figuras de Edipo y Fausto, hasta su problematización en el psicoanálisis, Foucault termina justificando su discriminación analítica por dos razones de distinto espectro y procedencia. De una parte, el interés general de poder abrir un nuevo dominio de indagación que sortee las confusiones y oscuridades derivadas de una idea demasiado amplia e imprecisa de ascesis. De otra, la motivación "personal" de estudiar la revolución como tipo de subjetividad, en tanto podría ser iluminada justamente desde las interrelaciones entre la ascesis orientada hacia la verdad y la encauzada hacia la realidad:

Creo que la fascinación ejercida por la idea de Revolución en la vida personal de los individuos, se debió en parte a la promesa de que esas dos formas de ascesis podían ser practicadas juntas: renunciar a esta realidad e ir hacia otra realidad mediante la adquisición de la verdad y la constitución de sí en tanto sujeto que conoce la verdad (2017: 110).

Como respuesta a una pregunta que le realizan en la última sesión del seminario, cuyo registro lamentablemente está incompleto, Foucault vuelve sobre la relación entre la atracción por la revolución y la preocupación ascética, añadiendo una última 
aclaración. Pensar la revolución desde la experiencia subjetiva implica no sólo dejar de considerarla únicamente como movimiento político y social, sino pasar a entenderla como "una figura histórica más que una posibilidad real o amenaza real" (2017: 286).

Las últimas menciones a la revolución previas al tratamiento del Cinismo que abordaremos aparte, se encuentran en el curso del Collège de France de 1983. La primera consiste en el ya aludido análisis de la segunda disertación de El conflicto de las facultades, donde Kant propone la revolución como signo rememorativo, demostrativo y pronóstico del progreso que impulsa al género humano. Que el filósofo discrimine lo esencial en "la simpatía de aspiración que roza el entusiasmo" por parte de los espectadores, le resulta a Foucault un modo sumamente sugerente de entender la revolución como acontecimiento. Al proponer que su contenido mismo carece de importancia pero que "su existencia en el pasado constituye una virtualidad permanente y, para la historia futura, la garantía del no olvido y la continuidad de una marcha", para el profesor francés constituye la otra cuestión que, junto a la de la Aufklärung, Kant definió para plantear el problema de su propia actualidad; interrogaciones que "no han dejado de asediar" a gran parte de la filosofía desde el s. XIX. La revolución como "valor operativo en la historia", "el entusiasmo revolucionario como agente de la Aufklärung" que implica la redistribución de las relaciones entre el gobierno de sí y el gobierno de los otros, confluye así en una de las dos tradiciones críticas que el filósofo alemán legó: no la de la analítica de la verdad en general, sino la que se pregunta "por el campo actual de las experiencias posibles"; "ontología de nosotros mismos" en la que Foucault procura inscribirse (2010g: 38-39).

La mención restante se encuentra en el marco del tratamiento de la parrhesía como acto que afecta el modo de ser de quien lo pronuncia y pone de manifiesto "el contrato del sujeto hablante consigo mismo", en tanto se constituye y reconoce como alguien que dice la verdad. Foucault propone considerar este aspecto como "la dramática del discurso verdadero", cuya vertiente política permitiría considerar distintas figuras con sus características propias. A la par del orador público, el consejero del príncipe, el ministro y el crítico, aparece el revolucionario: “¿Quién es el que se levanta, en medio de una sociedad, y dice: digo la verdad, y digo la verdad en nombre de algo que es la revolución que voy a hacer y que vamos a hacer juntos?" (84-86). Pregunta que quedará suspendida ya que, como en otros casos, no se trata más que de una indicación que no recibirá desarrollo en el curso.

Recapitulando entonces lo que arrojan esta serie de comentarios dispersos, un primer punto a destacar es que se introducen en relación con asuntos neurálgicos de las problematizaciones de cada curso; en función de los cuales pueden inferirse rasgos de la subjetivación revolucionaria. Enmarcada en el análisis de las relaciones entre gobierno y verdad, en 1980 la experiencia revolucionaria aparece ligada a matrices morales y no sólo políticas de conducción, luego de haber despejado la concepción utilitaria del conocimiento de la verdad y haber clarificado su enlace íntimo con las operaciones de subjetivación que requiere el ejercicio del poder. Tanto la espiritualidad como la 
conversión que encuadran las referencias de 1982, son motivos centrales que aparecen a partir de la reinscripción del imperativo del conocimiento de sí (gnothi seauton) en la inquietud más amplia del cuidado de sí (epilemeia heautou) - movimiento exegético rector de la investigación de ese año, cuyo corolario mayor es que la relación entre sujeto y verdad implica una serie de técnicas, procedimientos, prácticas reflexivas y en relación con otros y el mundo; toda una conformación del sí mismo y vivencia de la realidad que excede la mera adquisición de conocimientos. La distinción entre las dos formas de ascesis que se proponen el mismo año, constituye una elaboración única que Foucault no retomará literalmente; pero allí se encuentra explicitado que la subjetividad revolucionaria reuniría la dos grandes orientaciones del trabajo ascético: la verdad como principio para la transformación de sí que prepara para afrontar el mundo, y el acceso a otra realidad como resultado de dicha transformación. Por último, la revolución es considerada nada menos que en la apertura del arco kantiano bajo el cual el profesor emplaza la indagación de 1983; la cual se cierra volviendo a hilvanar la cuestión de la Aufklärung con la posibilidad de una historia de la filosofía como movimiento de la parrhesía (Cfr. 2010g: 355), justamente el otro término junto al cual es evocada. En conjunto, la revolución se entiende aquí como signo histórico de la posibilidad de modificar las relaciones de gobierno que forma parte de la genealogía del horizonte actual de experiencias; signo que el discurso del revolucionario evoca como interpelación en medio de la sociedad y como forma de subjetivarse en relación con la verdad y la realidad.

Un segundo aspecto notable, aunque en cierto modo implícito, es el reconocimiento que Foucault traduce de la importancia y vigencia del análisis en clave de ideología al subrayar repetidamente su oposición mediante una explicación de sus deficiencias (cursos de 1980 y 1981). La insistencia sobre ello demuestra la necesidad de despejar ese enfoque de la relación entre subjetividad y verdad inmediatamente asociado con -e incluso tomado como la inteligibilidad de- la resolución subjetiva a la revolución; aunque toca el núcleo de la experiencia, lo hace para el profesor de manera inadecuada e insatisfactoria. La misma operación de reconocimiento y crítica se advierte en las dos referencias que aparecen en Hermenéutica del sujeto, donde la espiritualidad y conversión subjetiva infaltables en el empeño por una transformación radical, se denuncian fagocitadas en la estructura del PCF.

Un gesto diferente puede apreciarse en cambio, como tercer rasgo, en el recurso a la espiritualidad, la conversión, la ascesis, la parrhesía, todas prácticas de elaboración reflexiva recuperadas de modelos éticos antiguos y que Foucault señala prácticamente desaparecidas en la filosofía, para pensar la experiencia revolucionaria. Si bien, como señala Gros, el profesor produce habitualmente "ese contraste marcado entre análisis minuciosos de algunas líneas de texto griego y una ampliación, una apertura súbitas hacia una historia secular de la subjetividad" (2010g: 389), en este caso parece reportar una especificidad. "Exclusividad" del tema de la conversión en la opción revolucionaria; única forma política y contemporánea mencionada en que pervive una dimensión espiritual del saber y un encuentro entre la orientación hacia la verdad y hacia otra 
realidad; dramática política de la veridicción que constituye al sujeto de la enunciación como parte de un sujeto plural - "pertenencia singular a un nosotros" en el cual debe situarse la redistribución de las relaciones de gobierno y la interrogación vertical del presente que supone la Aufklärung (Foucault, 2010g: 31), nosotros agente de la revolución "que vamos a hacer juntos". Prerrogativas todas que apuntan una unicidad o rareza, pero a la vez, en la forma de una generalidad esquemática o modélica: la revolución como tipo de subjetividad, que tiene su historia, como un estilo, un modo de existencia ligado a la transformación de la realidad.

En relación con ello, el cuarto y último punto a distinguir es la posibilidad, como resultado de las precisiones anteriores, de deducir la meta a la que conduce el desplazamiento del estudio de la revolución como proceso social y político. Teniendo en cuenta lo de la norma y el deseo desarrollado en el apartado anterior y atendiendo a la revolución como "virtualidad permanente" no sólo en la lectura de Kant sino en las reflexiones sobre Irán, "valor operativo en la historia" tanto para los límites que se deben interponer siempre al ejercicio del poder como para vislumbrar las posibilidades del presente, la concepción de la revolución como figura histórica propuesta por Foucault en el seminario de 1982, permite reunir todas esas notas. ¿Figura histórica de qué? En función de las observaciones compiladas, se trataría de la revolución como figura ascética de una ética particular y con sus notas distintivas, tal como puede hablarse de la ética platónica, estoica, cristiana. Ética en que la ethopoiesis se vincula a la transformación de la realidad; es decir, la configuración del propio modo de ser y conducirse, de relacionarse con uno mismo, los demás y el mundo, según una relación con la verdad que exige conmover a la vez la propia subjetividad y el mundo. Esta conmoción conjunta es precisamente la que Foucault encontrará representada y actuada en la forma de vida Cínica.

Introducida en El coraje de la verdad a partir de la distinción entre dos grandes líneas de desarrollo -no excluyentes entre sí- de la veridicción socrática, la que conduce a la ontología del yo o metafísica del alma y la orientada hacia el bios o estilo de existencia, la vida de los Cínicos instituye para Foucault (2010h) una relación con la verdad que reduce al mínimo su fundamentación teórica y maximiza su suporte en actos y modos de relación - ascesis realizada enteramente como operación material sobre la manera de ser y conducirse hacia los otros y el mundo común, que permite al profesor ampliar "la autonomía relativa con respecto a la metafísica" (348) y reforzar su interpelación para un presente post-metafísico. Sin embargo, llegando a su tratamiento a través de la reconstrucción efectuada, la experiencia cínica asume a nuestro parecer una significación y efectos más precisos, tanto en el pensamiento foucaultiano como para la actualidad de la problematización ética, que los que reportan en general las genealogías en términos de ampliación, variación y enriquecimiento de la perspectiva sobre la supuesta evidencia de lo dado. 


\section{ÉTICA MATERIALISTA Y EL RETORNO DE LA REVOLUCIÓN}

La posibilidad de concebir la revolución como figura ascética se inscribe y emerge del tipo de aproximación que Foucault propone sobre elementos centrales de la reflexión ética. No sólo la redefinición de la ascesis recién expuesta, sino el entendimiento de la experiencia como correlación entre formas de saber, relaciones de poder y pragmáticas de sí, la primacía allí concedida a las prácticas para iluminar la subjetividad en términos relacionales y forma constituida entre técnicas de sujeción vehiculizadas por el gobierno y procedimientos de auto-subjetivación, al igual que el planteo del ejercicio de la libertad vinculado a una percepción de la realidad con sus coeficientes de necesidad y contingencia histórica; comportan un enfoque singular para la problematización ética.

Sin recurrir a una teoría del sujeto, la conciencia, supuestos metafísicos o universales antropológicos, y apartada asimismo tanto de una propuesta normativa como del relativismo, la tematización ética asume en la óptica del profesor francés una relación con la verdad que, como indica Chevallier, se da "en el interior de una forma histórica y colectiva que se llama «régimen de verdad» (la ética no existe al aire libre, no nace $e x$ nihilo)" (2013: 65) y abre, en palabras de Negri "una nueva materialidad de los modos de vida" cuyo horizonte en la ontología histórica de nosotros mismos señala "un ser común, donde la dependencia recíproca y multilateral de las singularidades construye el único terreno sobre el cual es posible cuestionar la realidad y buscar la verdad" (2015: 181). En esta línea, la lectura que Foucault desarrolla del Cinismo añade dos especificaciones fundamentales.

En primer lugar, en contrapunto con "la experiencia metafísica del mundo", este movimiento plantea una "experiencia histórico-critica de la vida" que postula en la alteridad el encuentro posible con la verdad (2010h: 326). Sin embargo, no es la alteridad en sí misma -el hecho de que "la verdad nunca es lo mismo" - el factor diferenciador, sino el modo de entenderla. Para la ética platónica, estoica, cristiana, tampoco la verdad se da inmediatamente en el estado de cosas o del alma; exigen una transformación hacia otro modo de ser y otra realidad, pero desde una otredad signada por la trascendencia: el mundo de las ideas, la armonía con la razón recta, la vida eterna, plantean como meta el acceso a una dimensión ya existente en su plenitud, y de la cual las vidas particulares se separan por la ignorancia, el vicio, el pecado. El Cinismo, en cambio, arraiga la alteridad en el plano de la inmanencia histórica: la vida verdadera y el verdadero mundo no aparecerán sino como forma futura del cambio de esta vida y de este mundo. Sin duda a aquellas éticas también les corresponde una forma de vida que manifiesta su relación con la verdad, pero para los Cínicos, al entender de Foucault, no hay verdad en otro lugar que en las prácticas, las relaciones, las vidas y el mundo común que las materializan - "el modo de vida no tiene el mero papel de una correspondencia armónica con el discurso"; es "condición de posibilidad" y "prueba" (183-184).

En segundo lugar y relacionado con ello, la vida que es objeto de preocupación no es sólo para un Cínico la suya propia, no es siquiera la de otros particulares. Foucault 
(2010h) subraya que aquí el cuidado de los otros coincide exactamente con el cuidado de sí; vigilancia simultánea y extendida por la cual este personaje "pone en cuestión la humanidad entera de la que forma parte" (324). En tanto critica las convenciones, las leyes, las instituciones, las opiniones compartidas en general, construcciones que involucran a todos y cada uno, se distingue de otro tipo de proselitismos filosóficos dirigidos a un grupo selecto o secta- como "una militancia abierta, universal, agresiva; un militantismo en el mundo, contra el mundo", a través de una "vida de combate y de lucha contra uno mismo y por uno mismo, contra los otros y por los otros" (298-299). Aunque el profesor reconoce el anacronismo que supone la expresión "vida militante", juzga que en ella precisamente, "una vida cuya alteridad debe conducir al cambio del mundo", el Cinismo constituye "la matriz o, en todo caso, el germen de una experiencia ética fundamental en Occidente" (301).

Considerando justamente la pervivencia histórica de dicha matriz, vuelve a aparecer la experiencia revolucionaria. Como "principio que determina cierto modo de vida", la revolución adoptó para Foucault en la Europa de los s. XIX y XX tres grandes formas que predominaron de manera alternada: la socialidad secreta, la organización instituida y el testimonio por la vida (2010h: 196). Centrándose en ésta última como vertiente preponderante a mediados del s. XIX a través del nihilismo ruso, el anarquismo europeo y americano, hasta el terrorismo como "paso al límite", el profesor señala que no dejó de resurgir como problema acuciante, desde el cual podría establecerse un contrapunto con el Partido Comunista Francés: habría que indagar de qué manera "un cinismo de la vida revolucionaria como escándalo de una verdad inaceptable, se opuso a la definición de una conformidad de existencia como condición para la militancia en partidos que se dicen revolucionarios" (198-199). Aunque aquí la mención es más extensa que las compiladas en el apartado anterior, la revolución como estilo de existencia no deja de quedar como indicación para un estudio futuro; e incluso no es la única práctica que se recupera: ciertas formas del ascetismo cristiano y la vida de artista o el arte en función contra-cultural, completan la continuación de la matriz cínica como forma de vida que testimonia la verdad. Y sin embargo, la experiencia revolucionaria es el único caso en que Foucault refiere la vida como militancia, y a la vez, resulta la más ajustada a aquella caracterización de la postura cínica: en contraste con el ascetismo cristiano, cumple con plantearse enteramente en el plano de la inmanencia histórica, y a diferencia de la sátira, el desenmascaramiento y la ruptura de la cultura y la vida corriente por el arte, no se consuma en la crítica sino que interpela a través de ella hacia una transformación de la realidad.

A la luz de estas observaciones, el tratamiento del Cinismo consuma entonces el escenario del retorno de la revolución en el pensamiento de Foucault. Alteridad de la verdad cuya realización depende de una militancia que exige por igual la transformación del sí mismo, los otros y el mundo - si añadimos estas especificaciones a las claves de la problematización foucaultiana mencionadas antes, y atendemos a la indicación de aquella "ética particular" a la que apuntaba la subjetividad revolucionaria en el apartado anterior, puede proponerse que la revolución retorna como figura 
ascética de lo que podría denominarse una ética materialista ${ }^{5}$. Es decir, una ética centrada en las prácticas, que plantea la relación entre subjetividad y verdad según el principio de la alteridad entendida como transformación de la vida y el mundo en la inmanencia histórica, y cuya fundamentación o punto de anclaje último no es una ontología metafísica ni un programa normativo, sino una experiencia histórica: la militancia como forma de vida, estilo de existencia. Precisamente en ésta apareció la contrafigura positiva a la normalización moral que Foucault criticaba en las estructuras del PCF y en el conservadurismo soviético.

La revolución como forma de vida constituiría entonces la posibilidad de la pervivencia de la revolución en ausencia del proceso revolucionario; es decir, la figura de una ética militante en que la vida es inescindible y a la vez prueba de la posibilidad de transformar la trama de relaciones que tejen la existencia común, el mundo. Sin recorrer in extenso la exposición que Foucault desarrolla del Cinismo, nos interesa recuperar algunos aspectos para especificar las notas distintivas de esta ética en vinculación con luchas actuales; en las cuales puede reconocerse asimismo una afinidad con apreciaciones del profesor en torno a la resistencia.

Un primer punto atañe al objeto de crítica que define, en consecuencia, el terreno de transformación. Desde el imperativo de "cambiar el valor de la moneda" (moneda: nomisma, en relación con nomos. ley o convención), los cínicos se dirigen al conjunto de la cultura, abarcando tanto las instituciones como los valores, opiniones y costumbres en lo que tienen de artificiosidad y generación de preocupaciones superfluas con respecto a la simpleza de la vida natural. La función de reducción que tienen sus prácticas desde el imperativo de la "animalidad" que Foucault subraya (2010h: 279), transfigura lo comúnmente aceptado en el dominio de las ideas en una materialización inaceptable, repelente; escándalo que asegura la atención pública y efectiviza la interpelación. Por un lado, tal objeto de ataque constituye un referente generoso en términos de incluir una variedad de luchas diferentes: todas las que pongan en cuestión modelos coactivos y de amplia aceptación - un supuesto rol de la mujer, una idea de estética corporal, un patrón de familia, una sexualidad normal, pero también representaciones de lo que debe ser el "orden" o la "seguridad", y asimismo lo que se consideran luchas "legítimas" o problemas "urgentes". Por otro lado, si aquel imperativo cínico puede extenderse en su función crítica, es preciso reparar que no apunta a reducir la vida a lo biológico o a una determinación natural; estrategia no sólo en la biopolítica sino en los embates actuales más reaccionarios contra el avance en materia de derechos. Como señala Lorenzini (2015), si los modos cínicos interpelan es porque transfiguran valores reconocibles por la comunidad y promueven la "constitución positiva de una serie de atributos" que cualifican la vida - el coraje, la autarquía, la franqueza, la libertad (184). La crítica está entonces ligada a la institución de nuevas

${ }^{5}$ Respecto del enfoque de Foucault como un materialismo, nos permitimos referir a Monge (2017) 
Julia Monge

formas de autopercepción y reconocimiento de los otros en la dimensión pública de la existencia.

En segundo lugar, la redefinición de la relación entre teoría y praxis o armazón dogmática y experiencia que propone el Cinismo al centrarse en la forma de vida, conlleva una reconsideración de la relación con la verdad que se opone a las hegemonías del saber y a sus efectos prescriptivos. Foucault (2010h) enfatiza que los cínicos se dirigían con la misma acidez al público en general, a gente distinguida socialmente y a los filósofos; denunciando sus pretensiones e imposturas pero haciendo a la vez accesible la buena vida a todos -sin distinción de estatus, género, edad- quienes tuvieran disposición a practicarla. En tal sentido, Goulet-Cazé, especialista en el movimiento, señala que expresan vivamente un problema de fondo "que sólo Sócrates antes de ellos planteó en la antigüedad: «¿se puede ser filósofo e inculto? ¿se puede concebir que la verdadera filosofía sea popular?» Para ellos, la respuesta era a todas luces afirmativa" (2013: 122). En vez de adecuar las prácticas a un saber privilegiado o régimen de verdad estipulado -sea la palabra revelada, la ley de la historia, la esencia de lo humano- en esta ética se trata de partir de experiencias concretas que en sus dolores y aspiraciones indican qué es lo que resulta invivible o intolerable; cómo es que respecto a la vida deseable, las luchas contra la explotación y dominación capitalista no pueden disociarse ni apartarse jerárquicamente de las luchas contra el racismo, el patriarcado, el colonialismo, la xenofobia, la violencia institucional, y también contra el poder médico, el disciplinamiento moral, el poder eclesiástico, el control mediático. En tanto "funcionario de la universalidad ética" (Foucault, 2010h: 314), el Cínico lega la militancia como forma de instituir, a través de las conexiones de las resistencias, una suerte de universalidad empírica del cuidado de sí correlativo al cuidado del mundo, contra el aislamiento y las soledades que precisa la dominación. La alteridad de la verdad exige una labor perpetuamente reiniciada que ningún dogma puede apresar: "no hacia la verdad de nuestro pasado sino hacia el pasado de nuestras verdades" (Morey, 2014: 39) que permite descubrir sus líneas de fragilidad y mutación, y hacia el futuro de esa humanidad que somos y aún no somos porque nunca está ya enteramente realizada; desplazada no por ideal o retenida en el origen olvidado o cielo perdido, sino por transitoria, siempre otra.

Un tercer y último punto atañe al carácter del Cinismo como matriz de conducta y manera de ser. Centrado en la relación entre el problema de la verdad y el estilo de existencia, Foucault hace notar que el movimiento estuvo desde sus comienzos transido de ambigüedad y fue objeto de valoraciones contrapuestas, dando históricamente lugar a "formas diversas, prácticas diferentes, estilos de existencia modulados según distintos esquemas" (2010h: 192). Entre la interpelación violenta y la soberanía oculta que desprecia como vanidad la gloria pública, entre el rechazo manifiesto y la relación intensa con los otros, entre una ascesis corporal sumamente rigurosa y la burla grosera en la parrhesía, el Cínico no busca seguidores, pretende interlocutores. Toda una enseñanza para reconocer que las características del provenir deben materializarse ya en las formas de organización interna y de relación externa entre las luchas: las 
jerarquías y privilegios empiezan por disolverse allí, al igual que asumir que la pluralidad y la disidencia no son obstáculos a suprimir, sino el motor para generar nuevos puntos de encuentros, para crear en el plano de las alianzas y estrategias. Como el arte de la existencia individual, el vivir juntos también es un arte, y así entendido resulta disyuntivo de hacer de la política materia de politicastros, gestión de empresarios o dedicación burocrática; al igual que de encerrar a la ética en la disyuntiva de tener que determinar criterios y reglas de acción de validez universal, o bien asumirse relativista y atenerse a que el ejercicio de la libertad es imponderable. Una ética que se apoya en experiencias históricas de crítica y transformación, puede dar lugar no a una sino a muchas formas de vida que traduzcan el principio de la alteridad; como la variedad de resistencias mencionadas antes y que a Foucault preocupaba salvaguardar. Si, como señala Sardinha (2011), las resistencias pueden ser pasivas o activas -limitarse a intentar eludir los mecanismos inclusivos del poder o disputar, en cambio, la institución de una nueva configuración de su ejercicio-, cabría añadir que la ascesis revolucionaria también tambalea esta distinción: incluye y transforma las primeras alimentándose de su carácter de oposición, pero empujándolas hacia prácticas propositivas y no meramente reactivas.

En conjunto, al plantear que el modo de hacer existir la alteridad en la inmanencia histórica es la transformación, y recuperado por Foucault como forma anfibia a la vez interior y exterior a la filosofía; "ética filosófica" que cuando la filosofía se redujo a la transmisión de doctrinas y desatendió el problema del arte de la existencia, pasó a "la vida revolucionaria" (2010h: 229), el Cinismo como germen de esa experiencia y a la vez clave de una ética actual que acoge su retorno, propicia de una nueva manera el difícil encuentro entre filosofía y política. Una ética materialista como nudo entre ambas, invita a pensar que dicha manera resulta más promisoria que los "Estadosfilosofías" que invirtieron de facto las orientaciones libertarias de ambas (Foucault, 2010b: 787), pero asimismo más provisoria -modesta, cautelosa y plural- que la Revolución como salvación -de la caída, la vía incorrecta y la mancha- del Hombre.

Sin duda esta ética, como lo reconocía Foucault cuando era consultado por los efectos concretos de sus genealogías, se debe mucho todavía a la imaginación y recreación -atendiendo, como señala Nehamas, que la creación no parte sin embargo de una tabula rasa, "demanda reorganizar lo dado; la innovación requiere manipular lo obsoleto" y "la vida, vista estéticamente, no es algo diferente" (1998: 178). Pero aun así, no faltan signos de su existencia. La militancia feminista que atraviesa las distinciones de clase, partidarias, nacionales; la lucha por nuevos derechos que instituyen formas de reconocimiento en otro tiempo inconcebibles; la organización de la economía popular que recusa su definición como "informal"; la afirmación de culturas populares y villeras que disputan el sentido de "la" cultura definida por y privilegiada para pocos; la emergencia de distintas estéticas que transmutan la exposición como vulnerabilidad en exposición como fiesta común, algarabía, rechazando el modelo sacrificial por un cuidado amoroso y un combate que no excluye el placer, pero también como memoria 
colectiva encarnada, intransigente a cualquier olvido o retroceso - todo ello ya está aquí para quien quiera verlo.

\section{CONCLUSIÓN. KYNISMOS Y CINISMOS}

Apartándonos de una consideración de las complejas y polémicas relaciones de Foucault con el (o los) marxismo(s), y centrándonos en su valoración de la revolución la cual, no obstante, no es fácil aislar de las primeras-, ensayamos proponer una lectura de un proyecto o sugerencia que el profesor no llegó a desarrollar. Al cabo no del todo en suspenso en sus indagaciones y encontrando experiencias actuales afines, entendemos que el retorno de la revolución como figura ascética de una ética materialista, puede admitirse no como una formulación cerrada sino como un relanzamiento de aquel plan o propuesta abierta tanto para las exégesis sobre el trabajo del francés, como para las militancias del presente.

Situándonos desde la inescindible vinculación entre reflexión y práctica que fue una de las apuestas salientes del trabajo de Foucault, consideramos que esta formulación puede contribuir, junto a otras, a variar y ampliar la polaridad que se ha trazado en torno a su problematización ética; a saber: dado que recusa explícitamente ser normativa, o bien contiene una normatividad velada, o bien es indefectiblemente relativista. Siendo que la rigidez de este dilema excede el caso del profesor y afecta más inquietamente nuestras posibilidades presentes, cabría preguntarse si no es hacerse de la libertad y del pensamiento una idea bien pobre el estipular la exigencia de una teoría prescriptiva como base de toda ética, o el considerar que un planteo que tiene en cuenta las relaciones de gobierno, las posibilidades y límites de los dominios de saber, la perspectiva genealógica sobre los modos de subjetivación, y todo ello en clave crítica, es equivalente a nada, a no tomar posición. Provengan por diestra o siniestra, a tales simplificaciones correspondería una respuesta cínica: hay muchas formas de llevar una vida no fascista, pero no se puede obligar a nadie a tomarse el trabajo de intentar comprenderlo y a aceptar que se puede promover otro mundo y otras relaciones aún si tener predefinida su configuración destinal, recurriendo a la historia como testimonio de experiencias afortunadas y desaciertos. Puesto que al final de cuentas no es ningún deber; es una elección. En contraste, lecturas más alentadoras como la de lofrida (2015) que propone que Foucault supo reunir las lecciones de Marx y Nietzsche oponiéndose de manera cierta al capitalismo pero sin renunciar al valor de la diferencia y la individualidad, plantean una apertura solidaria y provocadora, ya que señalan alternativas de problematización que es preciso proseguir.

En esta línea, son experiencias y desafíos actuales los que al manifestar nuevas formas de subjetivación ético-políticas, a la vez individuales y colectivas, de oposición y afirmación, invitan a pensar este particular retorno de la revolución. Sin pretender ser exhaustivos, hemos mencionado algunas experiencias donde a nuestro entender cobra un referente concreto la idea de una ética materialista. Con todo lo que puede tener de provisoria, quizás alcanza a indicar que cuando se reúnen la inquietud por la verdad, la 
revolución y la vida; una filosofía del saber, del poder y la ética puede volver a ser puede llegar a ser- un saber, una política y una ética de la existencia. Cuando se encuentran, además, en el modo de la alteridad y la militancia, no se trata de otra cosa que del mundo y de esa humanidad que nunca está del todo ya presente, que siempre está llegando y desplazándose hacia otra transformación.

Considerando el devenir infame que tuvo el calificativo "cínico", Sloterdijk (2003) propone dos formas de historia que podrían permitir imaginar el porvenir de esa tríada de revolución, vida y verdad: la historia kínica, que encarna el espíritu de aquellos raros personajes de la antigüedad, y la historia cínica, impregnada del sentido modificado del término. Esta última, "ve en todas las cosas terrenales un círculo desesperante", tanto en la vida de los pueblos como en la de los individuos, "«no hay nada nuevo bajo el sol» es su lema", pero seguirá "marchando sobre los cadáveres de aquellos que fueron lo suficientemente ligeros para creer que podían ponerse en el camino de la voluntad de poder, del imperio milenario, de la «misión» histórica" (433). La otra,

\begin{abstract}
concepción histórica "materialista", sigue conteniendo infinidad de posibilidades para "otra historia" y para una historia de lo otro. Una historia real de lo otro solo puede ser escrita por aquellos que son lo otro y los otros y que se han decidido a dejar vivir esa alteridad que para ellos reivindican, la libertad de ser así [...] Así tiene que ser la historia; tiene que partir de algo y llegar a algo que viva ahora y que se toma cada vez más vida y derechos vitales para el ahora y el después. Lo que en un nivel está passé, en el nivel del saber vivo no puede ser pasable (435).
\end{abstract}

BiBLIOGRAFÍA

CHEVALLIER, Philippe. (2013). "Vers l'éthique. La notion de «régime de vérité» dans le cours Du gouvernement des vivants", en LORENZINI, Daniele; REVEL, Ariane; SFORZINI, Arianna (Dir.). Michel Foucault: éthique et vérité 1980-1984. Paris: Librairie Philosophique J. Vrin.

CHOAT, Simon. (2010). Marx through post-structuralism. Lyotard, Derrida, Foucault, Deleuze. London: Continuum.

FOUCAULT, Michel. (1994). "Le savoir comme crime", en EWALD, François; DEFERT, Daniel (Eds.). Dits et écrits II/ 1976-1979. Paris: Gallimard. 
(2000a). "No al sexo rey", en MOREY, Miguel (Introd. y trad.) Michel Foucault. Un diálogo sobre el poder y otras conversaciones. Madrid: Alianza.

-------- (2000b). "Poderes y estrategias", en MOREY, Miguel (Introd. y trad.) Michel Foucault. Un diálogo sobre el poder y otras conversaciones. Madrid: Alianza.

-------- (2006). Seguridad, territorio, población. Curso en el Collège de France 19771978. Buenos Aires: Fondo de Cultura Económica.

(2007). Nacimiento de la biopolítica. Curso en el Collège de France 19781979. Buenos Aires: Fondo de Cultura Económica.

-------- (2008). La hermenéutica del sujeto. Curso en el Collège de France 1981-1982. Buenos Aires: Fondo de Cultura Económica.

------- (2010a). “¿Es inútil sublevarse?”, en MOREY, Miguel et al. (Introd., trad. y ed.). Obras esenciales. Barcelona: Paidos.

(2010b). "La filosofía analítica de la política", en MOREY, Miguel et al. (Introd., trad. y ed.). Obras esenciales. Barcelona: Paidos.

------- (2010c). "Conversación con Michel Foucault", en MOREY, Miguel et al. (Introd., trad. y ed.). Obras esenciales. Barcelona: Paidos.

-------- (2010d). "La verdad y las formas jurídicas", en MOREY, Miguel et al. (Introd., trad. y ed.). Obras esenciales. Barcelona: Paidos.

- (2010e). "Preguntas a Michel Foucault sobre la geografía", en MOREY, Miguel et al. (Introd., trad. y ed.). Obras esenciales. Barcelona: Paidos.

- (2010f). "Verdad y poder", en MOREY, Miguel et al. (Introd., trad. y ed.). Obras esenciales. Barcelona: Paidos.

(2010g). El gobierno de sí y de los otros. Curso en el Collège de France 19821983. Buenos Aires: Fondo de Cultura Económica. 
(2010h). El coraje de la verdad. Curso en el Collège de France 1983-1984. Buenos Aires: Fondo de Cultura Económica.

(2012). "Metodología para el conocimiento del mundo: cómo deshacerse del marxismo", en CASTRO, Edgardo (Ed.). El poder, una bestia magnifica. Sobre el poder, la prisión y la vida. Buenos Aires: Siglo Veintiuno Editores.

(2013a). "La filosofía estructuralista permite diagnosticar lo que es el "hoy»", en CASTRO, Edgardo (Ed.). ¿Qué es usted, profesor Foucault? Sobre la arqueología y su método. Buenos Aires: Siglo Veintiuno Editores.

(2013b). “Acerca de la genealogía de la ética. Un panorama del trabajo en curso", en CASTRO, Edgardo (Ed.). La inquietud por la verdad. Escritos sobre la sexualidad y el sujeto. Buenos Aires: Siglo Veintiuno Editores.

(2014a). Del gobierno de los vivos. Curso en el Collège de France 1979-1980. Buenos Aires: Fondo de Cultura Económica.

- (2014b). Subjetivité et vérité. Cours au Collège de France 1980-1981. Paris: Seuil/Gallimard.

(2017). Dire vrai sur soi-même. Conférences prononcées à I'Université Victoria de Toronto, 1982. Paris: Librairie Philosophique J. Vrin.

GARO, Isabelle. (2011). Foucault, Deleuze, Althusser \& Marx. La politique dans la philosophie. Paris: Demopolis.

GOULET-CAZÉ, Marie O. (2013). "Michel Foucault et sa visión du Cynisme dans Le Courage de la vérité", en LORENZINI, Daniele; REVEL, Ariane; SFORZINI, Arianna (Dir.). Michel Foucault: éthique et vérité 1980-1984. Paris: Librairie Philosophique J. Vrin.

IOFRIDA, Manlio. (2015). "Michel Foucault entre Marx et Burckhardt : esthétique, jeu et travail", en LAVAL, Christian; PALTRINIERI, Luca; TAYLAN, Fehrat (Dir.). Marx \& Foucault. Lectures, usages, confrontatioms. Paris: La Decouverte.

LEMKE, Thomas (et al.). Marx y Foucault. Buenos Aires: Nueva Visión. 
LORENZINI, Daniele. (2015). Étique et politique de soi. Foucault, Hadot, Cavell et les techniques de /'ordinaire. Paris: Librairie Philosophique J. Vrin.

MONGE, Julia. (2017), "Para un materialismo de la coyuntura: Foucault y Althusser", Dorsal. Revista de Estudios foucaultianos, nº 3, pp. 91-118.

--(2018), "Omnes, singulatim y otra vez omnes. sobre la cuestión de la voluntad y su inteligibilidad estratégica en Michel Foucault", Hybris. Revista de Filosofía. Volumen 9, № 1, pp. 63-96.

MOREY, Miguel. (2014). Lectura de Foucault. Madrid: Sexto Piso.

NEGRI, Antonio. (2015). "La subjectivité retrouvée. Une expérience marxiste de Foucault", en LAVAL, Christian; PALTRINIERI, Luca; TAYLAN, Fehrat (Dir.). Marx \& Foucault. Lectures, usages, confrontatioms. Paris: La Decouverte.

NEHAMAS, Alexander. (1998). The art of living. Socratic reflections from Plato to Foucault. California: University of California Press.

READ, Jason. (2003). READ, J. The Micro-Politics of Capital. Marx and the Prehistory of the Present. Albany: SUNY Press.

SARDINHA, Diogo. (2011). Ordre et temps dans la philosophie de Foucault. Paris: L'Harmattan.

SLOTERDIJK, Peter. (2003). Crítica de la razón cínica. Madrid: Siruela. 